\title{
Potential anti-osteoporotic effect of Allolobophora caliginosa extract in orchiectomized rats
}

\author{
Ayat Youssef, Ahmed Baiomy, Sohair Ramadan Fahmy, Ayman Mohamed*, Dalia Saad, Reham Desoky \\ Zoology Department, Faculty of Science, Cairo University, Giza, Egypt
}

\begin{abstract}
Osteoporosis is defined as a universal skeletal disorder. The medicinal importance of earthworms has been known from time immemorial. The present investigation was designed to assess the antiosteoporotic efficacy of the earthworm, Allolobophora caliginosa extract (AcE) in bilaterally orchiectomized rats (OCX) to elicit the underlying in vivo mechanism. Twenty-eight male rats were divided into two groups. The first group (7 rats/group) represented sham-operated rats, while the second group (21 rats/group) underwent bilateral orchidectomy (OCX). The second group was randomly subdivided into three subgroups; OCX and A. caliginosa extract (AcE) (100 or $200 \mathrm{mg} / \mathrm{kg}$ body weight/day) treated subgroup. Administration of AcE to OCX rats increased femoral bone mineral density (BMD), bone mineral content (BMC), calcium (Ca), phosphorus (P), and calcitonin level, as compared to OCX rats. On the other hand, administration of AcE to OCX rats significantly decreased serum alkaline phosphatase (ALP) activity and parathyroid hormone (PTH) level compared to OCX rats. The present study showed that AcE is a beneficial novel natural antiresorptive agent. Its anti-osteoporotic effects may positively impact osteoblast differentiation, particularly bone mineralization, and higher osteoblast activity account for bone formation, preventing osteoporosis.
\end{abstract}

\section{Keywords:}

Allolobophora caliginosa extract, Antiresorptive activity, Bone mineralization, Male osteoporosis, Orchiectomized rats

\section{INTRODUCTION}

Osteoporosis is defined as a universal skeletal disorder and is often called a silent disease of aging because bone loss occurs without symptoms until microarchitectural deterioration and bone fracture occur ${ }^{1}$. In addition to causing pain, osteoporotic fractures can lead to deformity, permanent disability, loss of independence, and even death ${ }^{2}$. The imbalance of bone remodeling with increased bone resorption is the pathophysiological process underlying osteoporosis ${ }^{3}$. In the Western world, epidemiological studies showed that 1 in 3 postmenopausal women and 1 in 5 men above 50 years of age would have an osteoporotic fracture in their lifetime. Although osteoporosis has an exceptionally high incidence in postmenopausal women, research on osteoporosis in men is still lacking ${ }^{4}$. Osteoporosis in men is associated with more significant morbidity and mortality than in women ${ }^{5}$.
Antiresorptive agents such as bisphosphonates, denosumab, teriparatide, and strontium ranelate are considered the major conventional therapy for postmenopausal osteoporosis in women ${ }^{6}$. Since synthetic drugs are often encountered with some adverse effects, treatment with natural products is now considered as an alternative approach in managing osteoporosis ${ }^{7}$. The etiology of osteoporosis in men is very diverse and multifactorial. Chronic diseases, lifestyle habits, medication use, male sex hormones, calcium intake, heredity, and aging are the most etiological factors of osteoporosis in men $^{8}$. Chronic administration reduces therapeutic effects, and toxicity is the main problem associated with antiosteoporotic drugs. Thereby, developing antiosteoporotic from natural products may reduce toxicity and maintain therapeutic effectiveness when used clinically. Natural products have proven to be highly efficient for treating osteoporosis, and, not amazingly, the variety of drugs based on natural products is enormous.

*Corresponding author:

*Ayman Mohamed Email: ayman81125@cu.edu.eg 
The medicinal importance of earthworms has been known from time immemorial ${ }^{9}$. Earthworms have a dense nutritional content because of their soil-based origin. The phylum Annelida, more commonly known as segmented or bristle worms, presents in a wide variety of environments ranging from terrestrial and freshwater to marine habitats ${ }^{10}$. Among the Annelida, Allolobophora caliginosa (A. caliginosa) belongs to the family Lumbricidae ${ }^{11}$. Moreover, the use of A. caliginosa confers certain beneficial advantages including antipyretic, antispasmodic, detoxic, diuretic, antihypertensive, antiallergic, antiasthmatic, spermatocidal, antioxidative, antimicrobial, anticancer, antiulceral and antiinflammatory activities ${ }^{12}$. Zhe et al. ${ }^{13}$ studied the effect of the Chinese Materia Medica standardized product extracted from Hirudo and Pheretima (Shuxuetong) against osteoporosis in rats. Moreover, $\mathrm{Diez}^{14}$ revealed the efficacy of the earthworm, Lumbricus rubellus soil cacaing extract in suppressing osteoclast cell formation, resulting in anti-resorptive activity in alveolar bone. The present investigation was designed to assess the antiosteoprotic efficacy of the A. caliginosa extract (AcE) in bilaterally orchiectomized rats (OCX), the animal model of male osteoporosis, and elicit the underlying in vivo mechanism.

\section{MATERIALS AND METHODS}

\subsection{Collection of earthworms}

Earthworms of species A. caliginosa were collected from commercial vermiculture at Giza Governorate and maintained in plastic tubs containing decomposed organic matter until used for the study.

\subsection{Preparation of earthworm extract}

Earthworm extract was prepared using a method described previously ${ }^{15}$. Briefly, 500 adult clitellated worms (900 mg/worm) were kept in $0.65 \% \mathrm{NaCl}$ at room temperature for $1 \sim 2 \mathrm{~h}$ until their digestive systems became clean with a few times of solution changes. Animals were kept out of the solution and minced with scissors. Three grams of earthworm tissue was homogenized in $40 \mathrm{ml}$ of chloroform-methanol solution and left overnight at $4^{\circ} \mathrm{C}$. The following day, $16 \mathrm{ml}$ of distilled water was added to the homogenate. Then the mixture was centrifuged at $2460 \times \mathrm{g}$ for $10 \mathrm{~min}$. Three clearly visible layers were obtained. The upper water/methanol layer was pipetted out, and evaporated on a rotavapor until no methanol was left. An opalescent fluid, $\mathrm{pH} 7$, was obtained, freeze-dried and kept at $4^{\circ} \mathrm{C}$ until use.

\subsection{Amino acid content of earthworm extract}

Amino acid content of earthworm extract was analyzed using High Performance Liquid Chromatography (HPLC). Earthworm extract $(0.01 \mathrm{~g})$ and $10 \mathrm{ml}$ of $6 \mathrm{~N} \mathrm{HC1}$ were added to the glass ampoule. After sealing with Bunsen burner flame, the ampoule was put into the oven $\left(105^{\circ} \mathrm{C}\right.$ for $\left.22 \mathrm{hrs}\right)$. After cooling, the extract was filtered and then evaporated to dry at $40^{\circ} \mathrm{C}$ under vacuum in a rotary evaporator. The residue was dissolved with $5 \mathrm{ml}$ of acetate buffer $(\mathrm{pH} 2.0)$, stored in plastic specimen bottles, and kept in the freezer. Ten microlitres of the hydrolyzed sample were loaded into the cartridge of the analyzer ${ }^{16}$.

\subsection{Heavy metals content of earthworm extract}

$100 \mathrm{mg}$ of the dry extract was mixed with $4 \mathrm{ml}$ conc. $\mathrm{HNO}_{3}$ and $2 \mathrm{ml}$ conc. $\mathrm{HCl}$ for $12 \mathrm{hrs}$. The mixture was heated in a closed Teflon bottle in the oven (at $150^{\circ} \mathrm{C}$ and $800 \mathrm{kPa}$ ) for $2 \mathrm{hrs}$. After cooling at ambient temperature, $50 \mathrm{ml}$ with ultrapure distilled water was added. Metal contents were determined using a $304 \mathrm{u} / \mathrm{c}$ Atomic Absorption Spectrometer ${ }^{17}$.

\subsection{Animals}

Healthy and pure strain male albino rats (Rattus norvegicus) weighing 150-170 g were procured from the Research Center (NRC), Egypt. The animals placed in a pathogen-free room and maintained under standard conditions $\left(28 \pm 2^{\circ} \mathrm{C} ; 55-60 \% \mathrm{RH}\right)$ with natural day and night cycle. They were fed on a standard diet of rats and given water ad libitum. The rats were kept for a week before the commencement of the experiment for acclimatization. Experimental protocols and procedures used in this study were approved by the Institutional Animal Care and Use Committee (CU-IACUC) (Egypt) (CU/I/F/53/18). All the experimental procedures were carried out in accordance with international guidelines for the care and use of laboratory animals.

\subsection{Surgical procedure of orchiectomy}

Rats were anesthetized with $50 \mathrm{mg} / \mathrm{kg}$ sodium pentobarbital that injected intra-peritoneally for generalized anesthesia. Surgical procedures were carried out in accordance with the regulatory guidelines set by the Guide for the Care and Use of Laboratory Animals of the NIH. Laparotomy was performed under antiseptic conditions. A ventral midline skin and muscle incision was made, starting at umbilicus \& continuing caudally for a few millimeters. Testis is pulled out through the incision and ligated with 4-0 absorbable surgical thread. Then carefully cut below the testis, ensuring no testicular tissue is remaining. The skin incision and muscle were sutured with nonabsorbable surgical thread. The same preparation was performed on animals in the sham 
operation group, allowing the authors to identify the testis without their removal visually. The rats were given $25 \mathrm{mg} / \mathrm{kg} / 12 \mathrm{~h}$ metamizole sodium as an analgesic and received IM injection of $4000 \mathrm{IU} / \mathrm{kg} / 24 \mathrm{~h}$ ampicillin for 2 days. The wound dressing was also applied every day for a week.

\subsection{Experimental design}

Twenty-eight male rats were divided into two groups. The first group (7 rats/group) represented shamoperated rats, while the second group (21 rats/group) underwent bilateral orchidectomy (OCX). After one week of recovery from orchidectomy surgery, the second group was randomly subdivided into 3 subgroups (7 rats/each subgroup). The first OCX subgroup was administered orally distilled water (vehicle) daily for 10 weeks. The other two OCX subgroups were administered orally A. caliginosa extract (AcE) (100 or $200 \mathrm{mg} / \mathrm{kg}$ body weight/day) for 10 weeks.

\subsection{Animals handling}

At the end of the tenth week, the experimental rats were anesthetized with sodium pentobarbital (150 $\mathrm{mg} / \mathrm{kg}$ ). Bone mineral density (BMD) and bone mineral content (BMC) of the femur and tibia were analyzed using DEXA (Dual energy X-ray absorptiometry). While the blood samples were collected in centrifuge tubes without anticoagulants. Left femora were excised, and the surrounding tissues were removed, then washed in cold saline and stored at $-80^{\circ} \mathrm{C}$ until used for oxidative stress parameters ${ }^{18}$.

\subsection{Biochemical analyses}

The appropriate clinical kits (Biodiagnostic, Egypt) were used for the determination of several parameters. Calcium and phosphorus contents in serum were measured according to Gindle et al. ${ }^{19}$ and ElMerzabani et al. ${ }^{20}$, respectively. Serum total alkaline phosphatase (ALP) was determined colorimetrically according to the method described by Belfield and Goldberg $^{21}$. Parathyroid hormone (PTH) was estimated using IRMA PTH kit (A11930, Beckman Coulter Company), and calcitonin was determined by DRGELISA kit according to Tiegs et al. ${ }^{22}$. Testosterone had been determined in line with the manufacturer's instructions of Spectrum Diagnostics kits (Giza, Egypt).

\subsection{Histopathology of the femur bone}

The rats were sacrificed at the end of the experiment. The femoral bones of a few rats from each group were utilized to examine the bone histology using hematoxylin \& eosin (H\&E) staining. The left femurbone samples were fixed in $10 \%$ formalin for 24 hours before being decalcified at $4{ }^{\circ} \mathrm{C}$ for 2 weeks using a $10 \%$ ethylene diamine tetraacetic acid (EDTA) solution. After that, bone samples were washed, dehydrated in ascending concentrations of ethanol, cleared with xylene, infiltrated, and embedded in paraffin wax. Thin sections of $5 \mu \mathrm{m}$ thick using a rotary microtome. Sections were stained with Hematoxylin \& Eosin stains (H\&E) for light microscope examination of the micro-architecture of the femur bone ${ }^{23-24}$.

\subsection{Scanning electron microscopy (SEM) of the femur bone}

For SEM evaluations, the proximal parts of the femora were trimmed in a coronal plane. They were treated with 5\% sodium hypochlorite solution (Commercial Bleach) for 4 hours to expose the epiphyseal and metaphyseal trabecular bone. Specimens were placed into $2.5 \%$ buffered glutaraldehyde solution. Tissues were dehydrated using acetone series with increasing degree. After the drying process, they were mounted on aluminum reservoirs by liquid silver and coated with gold/palladium using Denton Vacuum, LLC Desk V sputter/etch unit coating device (Denton vacuum LLC, Moorestown, $\mathrm{NJ})^{25}$. The tissue loaded was evaluated and captured
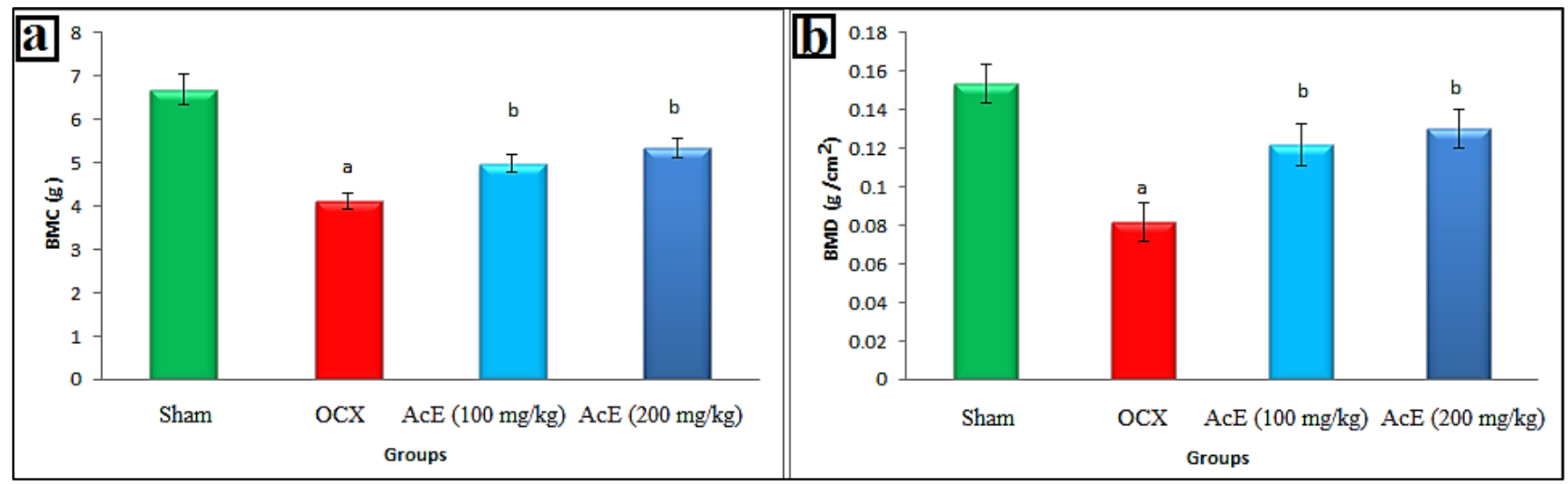

Figure 1. Effect of AcE on BMC (a) and BMD (b) levels of OCX rats. Values are means $\pm \mathrm{SE}$ ( $\mathrm{n}=7$ per group). a $=$ significant difference $(p<0.05)$ relative to sham group, $b=$ significant difference relative to untreated OCX rats. The comparisons within groups were evaluated utilizing one way ANOVA. 
Table 1. Amino acid composition of earthworm extract.

\begin{tabular}{lc}
\hline Amino acid & \% in dray mass \\
\hline Alanine & 0.40 \\
Arginine & 0.65 \\
Methionine & 0.40 \\
Aspartic & 1.00 \\
Glutamic & 1.70 \\
Glycine & 0.39 \\
Histidine & 0.71 \\
Isoleucine & 0.55 \\
Leucine & 0.62 \\
Lysine & 0.58 \\
Phenylalanine & 0.51 \\
Serine & 0.60 \\
Threonine & 0.50 \\
Cysteine & 0.37 \\
Tyrosine & 0.52 \\
Valine & 0.58 \\
Proline & 0.58 \\
\hline
\end{tabular}

Table 2. Metal contents of earthworm extract.

\begin{tabular}{cc}
\hline Metal & Concentration (mg/kgm) \\
\hline $\mathrm{Zn}$ & 100 \\
$\mathrm{Cu}$ & 15.35 \\
$\mathrm{Cr}$ & 0.75 \\
$\mathrm{Cd}$ & 0.37 \\
$\mathrm{~Pb}$ & 0.10 \\
$\mathrm{Hg}$ & - \\
$\mathrm{Ni}$ & - \\
\hline
\end{tabular}

Table 3. Effect of AcE on Testosterone level (ng/ml) markers of OCX rats.

\begin{tabular}{cc}
\hline Groups & Testosterone level \\
\hline Sham & $1.87 \pm 0.35$ \\
OCX & $<0.07^{\mathrm{a}}$ \\
$\operatorname{AcE}(100 \mathrm{mg} / \mathrm{kg})$ & $<0.07^{\mathrm{a}}$ \\
$\operatorname{AcE}(100 \mathrm{mg} / \mathrm{kg})$ & $<0.07^{\mathrm{a}}$ \\
\hline
\end{tabular}

Values are means $\pm \mathrm{SE}(\mathrm{n}=7$ per group). a=significant difference relative to sham group $(p<0.05)$. The comparisons within groups were evaluated utilizing one way ANOVA.

using a scanning electron microscope (JEOL, JSM-5200).

\subsection{Statistical analysis}

Values were expressed as means \pm SE. The comparisons within groups were evaluated utilizing one way analysis of variance (ANOVA) with Duncan post hoc test which was used to compare the group means. A $p<0.05$ was considered statistically significant. SPSS, for Windows (version 15.0) was used for the statistical analysis.

\section{RESULTS}

\subsection{Amino acid contents and heavy metals found in earthworm extract}

The extract contains essential and non-essential amino acids with high nutritional value (Table 1).
$\mathrm{Zn}, \mathrm{Cu}, \mathrm{Cr}, \mathrm{Cd}$, and $\mathrm{Pb}$ are the main metals present in the earthworm extract (Table 2).

\subsection{Testosterone, BMD and BMC}

Following orchidectomy, testosterone levels were monitored. The data showed that OCX rats had a significant decrease $(p<0.05)$ in testosterone levels, compared with sham group (Table 3 ). We then examined femoral BMC and BMD and the results demonstrated that, the femoral $\mathrm{BMC}$ and $\mathrm{BMD}$ were decreased significantly $(p<0.05)$ in the OCX group compared to the sham group. AcE (100 and $200 \mathrm{mg} / \mathrm{kg}$ body weight) significantly alleviated the decreasing effect of OCX on BMD (Figure 1).

\subsection{Calcium and phosphorus contents}

Orchidectomy induced a significant decrease 
$(p<0.05)$ in the serum calcium and phosphorus contents when compared to the sham-operated group (Figure 2a and Figure $2 b$ ). On the other hand, treatment with AcE (100 and $200 \mathrm{mg} / \mathrm{kg}$ body weight) caused a significant increase $(p<0.05)$ in the serum calcium $(\mathrm{Ca})$ and phosphorus $(\mathrm{P})$ contents as compared to OCX rats (Figure $2 \mathrm{c}$ ).

\subsection{Alkaline phosphatase activity}

Data presented in Figure 2 showed that orchidectomy induced a significant increase $(p<0.05)$ in the serum ALP activity as compared to sham-operated rats. Meanwhile, administration of AcE (100 and $200 \mathrm{mg} / \mathrm{kg}$ body weight) decreased significantly $(p<0.05)$ the serum ALP activity as compared to OCX rats.

\subsection{Serum calcitonin and PTH levels}

The serum calcitonin level of OCX rats was decreased significantly $(p<0.05)$ in comparison with rats of the sham group (Figure 2d). Concerning serum PTH, OCX rats showed a significant increase $(p<0.05)$ in their concentration compared with the sham group. On the other hand, administration of AcE (100 and 200 $\mathrm{mg} / \mathrm{kg}$ body weight) restored significantly $(p<0.05)$ the serum calcitonin and PTH levels near to their standard value (Figure 2).

\subsection{Histopathology of the femur bone}

Histological sections of the femur bone from rats of the sham group showed the articular cartilage
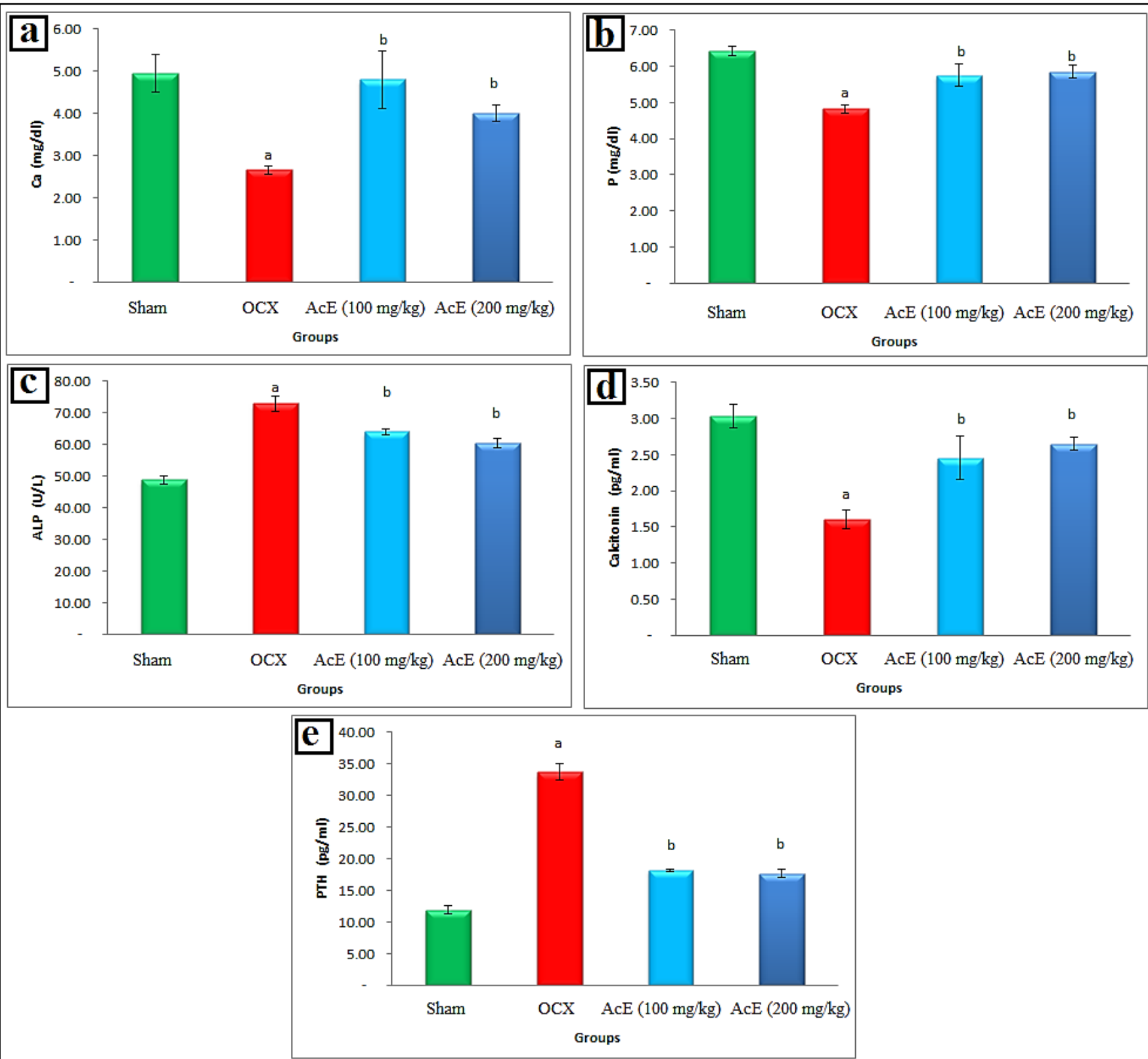

Figure 2. Effect of AcE on Ca (a), P (b), ALP (c), calcitonin (d), and PTH (e) levels of OCX rats. a=significant difference $(p<0.05)$ relative to sham group, $b=$ significant difference relative to untreated OCX rats. The comparisons within groups were evaluated utilizing one way ANOVA. 


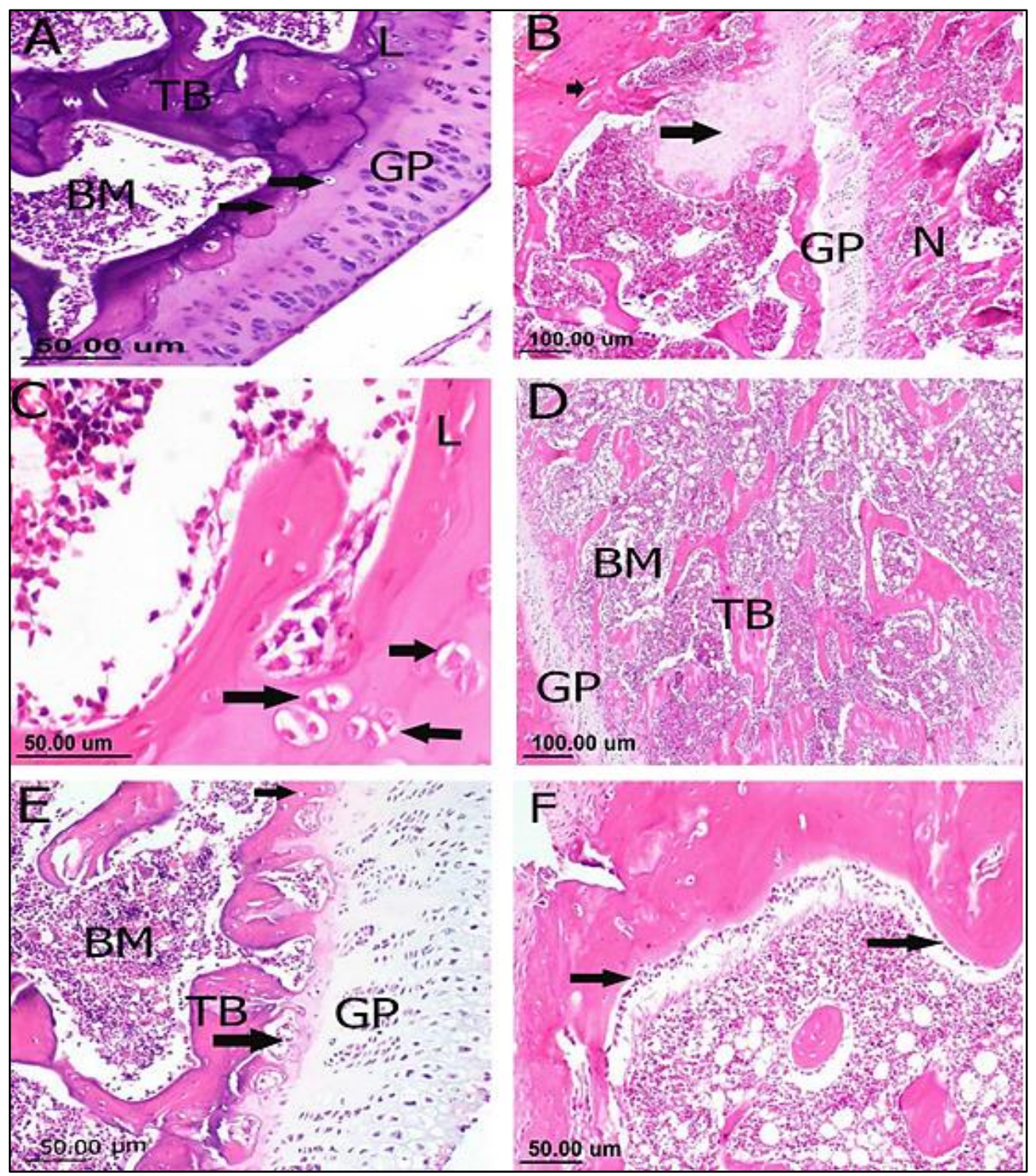

Figure 3. Photomicrographs of the rat femur stained by Hematoxylin and Eosin of the studied groups: (A) sham group showed the growth plate (GP), osteoblasts appeared cuboidal (arrows), osteocytes resided in their lacunae (L), better connected trabecular bone (TB) surround bone marrow (BM). (B) OCX group showed disorganization of the growth plate (GP), many trabeculae suffered from necrosis (N), showed defective mineralization (arrow) and osteoporotic cavities (arrow head). (C) OCX group showed increased number of osteoclasts caused dissolution and absorption of bone (arrows) and empty large lacunae (L). (D) AcE (100 mg/kg) group showed the growth plate with different healthy zones (GP) and relative repair of the trabecular bone (TB) surround bone marrow (BM). (Bar=100 $\mu \mathrm{m})$. (E) AcE $(200 \mathrm{mg} / \mathrm{kg})$ group showed the growth plate with different healthy zones (GP), osteoblasts appeared cuboidal (arrows) and better connected trabecular bone (TB) surround bone marrow (BM). (F) AcE (200 mg/kg) group showed activated osteoblasts (arrows).

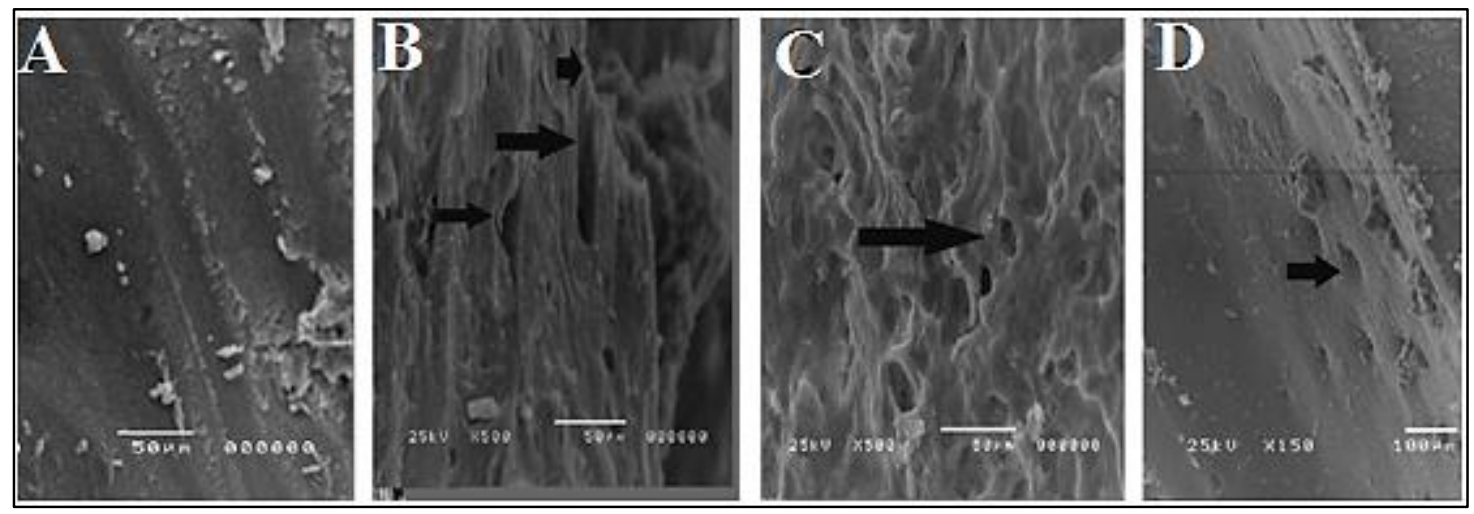

Figure 4. Scanning electron micrographs of the femoral proximal metaphysis in rats. (A) sham group, represents the normal bone structure and trabecular integrity. (B) OCX group showing disintegration in bone architecture, combined with resorption cavities ( $\mathrm{arrow}$ ). (C) AcE (100 mg/kg) group showing tight or loose collagen fibrils on the bottom of the lacuna (arrow). (D) AcE $(200 \mathrm{mg} / \mathrm{kg}$ ) group showing reduction in holes and the arrangement of fibrillar collagen make smooth surfaces (arrow). 
composed of hyaline cartilage and attached to the cortical bone of the head of the femur. The hyaline cartilage contained glycosaminoglycans in the matrix that synthesized and maintained by the chondrocytes. Bone sections showed active growth plate. Bone tissue was of the compact type, covered by two layers, the periosteum and the endosteum. Osteocytes are found in lacunae. The head of the femur bone was formed of cancellous bone composed of a network of irregular bone lamellae between which osteocytes resided in their lacunae. Cancellous bone of sham rats revealed normal architecture of trabecular bone. Where trabecular structure showing normal, dense and better connected trabecular bone structure, leads to a decrease of intertrabecular cavities. The bone forming osteoblasts appeared cuboidal with large nuclei located on the surface of the bone and responsible for synthesizing the organic components of the bone (Figure 3A).

In the case of OCX rats, examination of the femur bone showed marked decrease in the thickness of the compact bone and decrease in the number of osteocytes with disorganization of the growth plate. Examined sections of model group showed a loss of bone mass, a weakening of the bones as their calcified supporting structures are replaced with fibrous tissue (Figure 3B). Moreover, many trabeculae suffered from necrosis, showed defective mineralization and were thin with decrease bone density and loss of the trabecular interconnectivity when compared to sham rats. Many osteoporotic cavities and empty large lacunae were observed in bone tissue associated with increased number of osteoclasts caused dissolution and absorption of bone (Figure 3C).

Examination of bone sections in rats treated with with ACE (100 \& $200 \mathrm{mg} / \mathrm{kg}$ body weight/day) showed that the number of osteocytes was increased. The growth plate showed different healthy zones of cartilage as compared with OCX rats. Many osteoporotic cavities were still present. Exhibited thicker trabeculae with increased interconnectivity, showing relative repair of the trabecular bone in comparison to OCX model group (Figure 3D and Figure 3E).

\subsection{Scanning Electron Microscopic (SEM) examina- tion}

In the sham group, the connectivity of trabecular bone in the metaphysis showed greater association, smooth surfaces of collagen (Figure 4A).

Orchiectomy, on the other hand, resulted in changes in normal bone architecture, including a reduction in femoral trabecular bone and disintegration of bone architecture, as well as resorption cavities and numerous cracks, thinning, tapering and breakage (Figure 4B).

Administration of ACE $(100 \mathrm{mg} / \mathrm{kg}$ body weight/day) alleviated the abnormalities induced by orchiectomy; on the bottom of the lacuna, tight or loose collagen fibrils presented and improved bone architecture, as compared to OCX rats (Figure 4C). Furthermore, in comparison to untreated OCX rats, administration of ACE ( $200 \mathrm{mg} / \mathrm{kg}$ body weight/day) ameliorated the changes in trabecular bone induced by orchiectomy and the morphology of the metaphysis remained nearly usual, improved the collagen, as evidenced by the reduction in holes and the arrangement of fibrillar collagen made smooth surfaces (Figure 4D).

\section{DISCUSSION}

Osteoporosis is a metabolic and chronic bone disease that results from a disturbance in the normal bone remodeling, tilting the balance to bone resorption over formation ${ }^{26}$. Globally, high mortality and morbidity rates of osteoporosis increased the inevitability of the development of a novel antiosteoporotic drug. Usually, in male osteoporosis patients, the morbidity and mortality of fracture are higher than those in the female population, which necessitates additional research on osteoporosis treatment in $\mathrm{men}^{27}$. For the therapeutic strategies of bone resorption during osteoporosis, it is vital to find an effective compound or drug that can block bone injuries. Several emerging findings have suggested that Earthworm extracts showed chemoprevention activity against osteoporosis ${ }^{13}$. The present study throws light for the first time on the therapeutic efficacy of $A$. caliginosa extract (AcE) against osteoporosis induced bilaterally orchiectomized rats.

In conjunction with the reports of Sakr et al. ${ }^{28}$, the present study revealed that OCX induced marked decreased $\mathrm{BMD}$ and $\mathrm{BMC}$ of the femur compared with the sham group. The marked decrease in BMD and BMC levels is a marker for bone resorption during osteopo$\operatorname{rosis}^{14}$.

In accordance with the report of Filipovic et al. ${ }^{29}$, the present investigation showed that OCX caused a marked decrease in the contents of both calcium and phosphorus in the serum as compared to the sham group. Agnusdei, et al. ${ }^{30}$ reported that testosterone deficiency is associated with impaired calcium balance, thereby reducing calcium absorption and increased renal excretion of calcium. It was reported that androgen is vital for maintaining trabecular bone mass and structure ${ }^{31}$. Treatment with AcE caused a marked increase in serum $\mathrm{BMD}, \mathrm{BMC}, \mathrm{Ca}$, and $\mathrm{P}$ levels, indicating maintenance of functional integrity of osteoblast. Bone remodeling is a lifelong process in that initiated by osteoclastic bone resorption and subsequent osteoblastic bone formation. The recorded improvement in the BMD and BMC in the OCX rats in the present study may be due to enhancement in the proliferation, differentiation, and matrix calcium deposition of osteoblasts following treatment 
with $\mathrm{AcE}^{32}$. The main element present in $\mathrm{AcE}$ was zinc. It was reported that zinc improves chondrocyte and osteoblast activities while reducing osteoclast activity, indicating that zinc plays a role in bone homeostasis and regeneration ${ }^{33}$. AcE is also rich in essential and nonessential amino acids. The protein and some amino acids, such as alanine and glycine, may help maintain bone health ${ }^{34}$. Fascinatingly, the present study suggested that $\mathrm{AcE}$ has a favorable effect on $\mathrm{Ca}$ absorption and its deposition in bone, contributing to increased BMD and BMC.

In conjunction with the report of Omrani, et al. ${ }^{35}$ the present investigation disclosed that the activity of ALP significantly increased in osteoporotic rats. Our results are consistent with the results of Dabaja, et al. ${ }^{36}$, who proved that low serum testosterone level in hypogonadal men correlates with increase in serum ALP. Treatment with AcE in the present study decreased the serum ALP activity significantly. These findings agreed with the antecedent study of Yuan-Tsung et al. ${ }^{32}$, who reported that AcE might positively affect osteoblast differentiation, particularly bone mineralization and higher osteoblast activity account for bone formation, which prevents osteoporosis. Meanwhile, ALP reduction after $\mathrm{AcE}$ would indicate a reduction in bone resorption and inhibition in the osteoclastic activities ${ }^{37}$.

In accord with the report of Filipović, et al. ${ }^{29}$, the present results revealed a significant elevation in PTH level and a significant reduction in calcitonin level of OCX rats. The hyperparathyroidism in osteoporotic rats may be attributed to calcium deficiency ${ }^{38}$. The present investigation suggests that testosterone deficiency leads to decreased calcium level in blood, which ultimately increases the PTH concentration, where calcium is the major regulator of PTH secretion ${ }^{30}$. Administration of AcE in the OCX rats significantly decreased PTH and increased calcitonin activities that may indicate a reduction of bone resorption and osteoclastic activities ${ }^{37}$.

\section{CONCLUSION}

From the present study results, it can be concluded that AcE is a useful novel natural antiresorptive agent. Again, the present study suggested that AcE has a favorable effect on $\mathrm{Ca}$ absorption and its deposition in bone, contributing to increased BMD and BMC. Administration of AcE in the OCX rats significantly decreased PTH and increased calcitonin activities, indicating a reduction in bone resorption and osteoclastic activities.

\section{ACKNOWLEDGEMENT}

The authors extend their appreciation to the Deanship of Scientific Research at the Faculty of
Science, Cairo University, Cairo, Egypt for supporting the current work.

\section{Conflict of interest}

The authors declare no conflict of interest.

\section{Funding}

None to declare.

\section{Ethics approval}

Experimental protocols and procedures used in this study were approved by the Institutional Animal Care and Use Committee (CU-IACUC) (Egypt) (CU/I/F/53/ 18). All the experimental procedures were carried out in accordance with international guidelines for the care and use of laboratory animals.

\section{Article info:}

Received July 25, 2021

Received in revised form October 31, 2021

Accepted October 31, 2021

\section{REFERENCES}

1. Deyhim F, Garica K, Lopez E, Gonzalez J, Ino S, Garcia M, et al. Citrus juice modulates bone strength in male senescent rat model of osteoporosis. Nutrition. 2006;22(5):559-63.

2. Goswami R. Primer on the metabolic bone diseases and disorders of mineral metabolism. Indian J Med Res. 2016;144(3): 489-90.

3. De Martinis M, Sirufo M, Ginaldi L. Osteoporosis: Current and Emerging Therapies Targeted to Immunological Checkpoints. Curr Med Chem. 2020;27(37):6356-72.

4. Ryu SJ, Ryu DS, Kim JY, Park J, Kim KH, Chin DK, et al. Bone Mineral Density Changes after Orchiectomy using a Scrotal Approach in Rats. Korean J Spine. 2015;12(2):55-9.

5. Yeh PS, Lee YW, Chang WH, Wang W, Wang JL, Liu SH, et al. Biomechanical and tomographic differences in the microarchitecture and strength of trabecular and cortical bone in the early stage of male osteoporosis. PloS One. 2019;14(8):e0219718.

6. Giusti A, Bianchi G. Treatment of primary osteoporosis in men. Clin Interv Aging. 2014;10:105-15.

7. Mohamed AS. Echinochrome Exhibits Antitumor Activity against Ehrlich Ascites Carcinoma in Swiss Albino Mice. Nutr Cancer. 2021;73(1):124-32.

8. Nayak S, Greenspan SL. Osteoporosis treatment efficacy for men: a systematic review and meta-analysis. J Am Geriatr Soc. 2017;65(3):490-5.

9. Bin Dajem S, Ali SB, Abdelrady OG, Salahaldin NM, Soliman AM, Kamal YM, et al. Allolobophora caliginosa coelomic fluid ameliorates gentamicin-induced hepatorenal toxicity in rats. Asian Pac J Trop Biomed. 2020;10(9):411-6.

10. Weigert A, Bleidorn C. Current status of annelid phylogeny. Org Divers Evol. 2016;16(2):345-62.

11. Römbke J, Dorow WHO, Jänsch S. Distribution and diversity of earthworms (Lumbricidae) in Hesse (Central Germany): current knowledge. Soil Org. 2018;90(3):171-85.

12. Balamurugan M, Parthasarathi K, Ranganathan LS, Cooper EL. Hypothetical mode of action of earthworm extract with hepatoprotective and antioxidant properties. J Zhejiang Univ Sci B. 2008;9(2):141-7.

13. Zhe Xu Xl, Li Y, Gaol H, He T, Zhang C, Hao W, et al. Shuxuetong injection simultaneously ameliorates dexamethasonedriven vascular calcification and osteoporosis. Exp Ther Med. 
2021;21(3):197.

14. Diez F. Guidelines for the diagnosis of osteoporosis by densitometric methods. J Manipulative Physiol Ther. 2002;25(6):403-15.

15. Hrzenjak T, Hrzenjak M, Kasuba V, Efenberger-Marinculić P, Levanat S. A new source of biologically active compoundsearthworm tissue (Eisenia foetida, Lumbricus rubellus). Comp Biochem Physiol Comp Physiol. 1992;102(3):441-7.

16. Dedeke GA, Owa SO, Olurin KB. Amino acid profile of four earthworms species from Nigeria. Agr Biol J N Am. 2010;1(2): 97-102.

17. Dai J, Becquer T, Rouiller JH, Reversat G, Bernhard-Reversat F, Nahmani J, et al. Heavy metal accumulation by two earthworm species and its relationship to total and DTPA-extractable metals in soils. Soil Biol Biochem. 2004;36:91-8.

18. Mohamed AS, Salah EL Din EY, Farag NA, Tawfik AA. The teratogenic mechanism of echinochrome as a hypoglycemic agent on wistar rats. Open Biomark J. 2019;9:79-83.

19. Weybrew JA, Matrone G, Baxley HM. Spectrophotometric Determination of Serum Calcium. Anal Chem. 1948;20(8): 759-62.

20. El-Merzabani MM, El-Aaser AA, Zakhary NI. A new method for determination of inorganic phosphorus in serum without deprotinization. J Clin Chem Clin Biochem. 1977;15(12):715-8.

21. Belfield A, Goldberg DM. Revised issue for serum phenyl phosphatase activity using 4-amino-antipyrine. Enzyme. 1971; 12(5):561-73.

22. Tiegs RD, Body JJ, Barta JM, Heath H. Secretion and metabolism of monomeric human calcitonin: effects of age, sex, and thyroid damage. J Bone Miner Res. 1986;1:339-49.

23. Feldman A, Wolfe D. Tissue processing and hematoxylin and eosin staining. In:Day C, editor. Histopathology: Methods and Protocols 1180. New York: Humana Press. 2014; p. 31-4.

24. Mamdouh S, Mohamed AS, Mohamed HA, Fahmy WS. The effect of zinc concentration on physiological, immunological, and histological changes in crayfish (Procambarus clarkii) as bio-indicator for environment quality criteria. Biol Trace Elem Res. 2022;200(1):375-84.

25. Panwar P, Du X, Sharma V, Lamour G, Castro M, Li H, et al. Effects of cysteine proteases on the structural and mechanical properties of collagen fibers. J Biol Chem. 2013;288(8):5940-50.

26. Kanis JA RJ, McCloskey E, Johansson V, Cooper H, Rizzoli CR. European guidance for the diagnosis and management of osteoporosis in postmenopausal women. Osteoporos Int. 2013; 24:23-57.
27. Kamel HK. Male osteoporosis: new trends in diagnosis and therapy. Drugs Aging. 2005;22(9):741-8.

28. Sakr HF, Hussein AM, Eid EA, Boudaka A, Lashin LS. Impact of Dehydroepiandrosterone (DHEA) on BoneMineral Density and Bone Mineral Content in a RatModel of Male Hypogonadism. Vet Sci. 2020;7(4):185.

29. Filipović B, Sosić-Jurjević B, Ajdzanović V, Trifunović S, Manojlović-Stojanoski M, Ristić N, et al. The effect of orchidectomy on thyroid $\mathrm{C}$ cells and bonehistomorphometry in middleaged rats. Histochem Cell Biol. 2007;128(2):153-9.

30. Agnusdei D, Civitelli R, Camporeale A, Parisi G, Gennari L, Nardi P, et al. Age-related decline of bone mass and intestinal calcium absorption in normal males. Calcifi Tissue Int. 1998; 63(3):197-201.

31. Mosekilde L, Vestergaard P, Rejnmark L. The pathogenesis, treatment and prevention of osteoporosis in men. Drugs. 2013; 73(1):15-29.

32. Yuan-Tsung Fu , Kuo-Yu C, Yueh-Sheng C, Chun-Hsu Y. Earthworm (Pheretima aspergillum) extractstimulates osteoblast activity and inhibitsosteoclast differentiation. BMC Complement Altern Med. 2014;14:440.

33. O'Connor JP, Kanjilal D, Teitelbaum M, Lin SS, Cottrell JA. Zinc as a Therapeutic Agent in Bone Regeneration. Materials (Basel). 2020;13(10):2211.

34. Jennings A, MacGregor A, Spector T, Cassidy A. Amino Acid Intakes Are Associated With Bone Mineral Density and Prevalence of Low Bone Mass in Women: Evidence From Discordant Monozygotic Twins. J Bone Miner Res. 2016;31(2): 326-35.

35. Saki F, Kasaee SR, Sadeghian F, Koohpeyma F, Omrani GHR. Investigating the effect of testosterone by itself and in combinationwith letrozole on 1,25-dihydroxy vitamin D and FGF23 in male rats. J Endocrinol Invest. 2019;42:19-25.

36. Dabaja AA, Bryson CF, Schlegel PN, Paduch DA. The effect of hypogonadism and testosterone-enhancing therapy on alkaline phosphatase and bone mineral density. BJU Int. 2015;115(3): 480-5.

37. Dharmawati I, Mahadewa T, Widyadharma I. Antibacterial Activity of Lumbricus rubellus Earthworm Extract Against Porphyromonas Gingivalis as the Bacterial Cause of Periodontitis. Open Access Maced J Med Sci. 2019;7(6):1032-6.

38. Reddy RN, Lakshmana M. Prevention of bone loss in calcium deficient ovariectonized rats by OST-6, a herbal preparation. J Ethnopharmacol. 2003;84(2-3):259-64. 